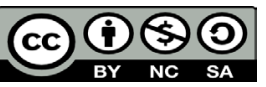

\title{
Visiones desde la tradición estética y filosófica para el mundo global -Diálogo entre Rafael Argullol y Tamara Djermanovic- ${ }^{1}$
}

doi:10.11144/Javeriana.uph31-62.ratd

Una palabra amistosa procedente del corazón de un hombre valiente, una sonrisa tras la que se oculta la devoradora grandeza del espíritu, es poco y es mucho, es como una fórmula mágica, que oculta la vida y la muerte en sus ingenuas sílabas, es como un agua espiritual que brota de lo profundo del monte y nos comunica la fuerza secreta de la tierra en sus gotas cristalinas.

Hölderlin, 1993: 29-30

INTERROGAR EL MUNDO, BUSCAR EL SENTIDO en medio de la dialéctica de la vida o examinar si el número, el arché, la idea, el daimon, la sustancia o el ser, dan constancia a un mundo cambiante, originó el pensamiento filosófico. En apenas dos siglos y medio, desde el siglo VI a.C hasta la muerte de Platón (347 aC), la filosofía se desplegó desde la especulación cuasi mitológica hasta el pensamiento que, en algunos aspectos, no ha sido superado hasta ahora. Los pitagóricos, el idealismo, el materialismo, el empirismo, el positivismo, la filosofía analítica, han planteado desde enfoques diferentes cuestionamientos acerca del mundo, del mismo modo, desde nuestro mirador actual, con el monopolio de las nuevas tecnologías, la preocupación por el medioambiente, la biotecnología, la crisis económica y otros aspectos que forman parte de la cotidianidad del ser humano del siglo XXI, los diversos temas filosóficos que siempre se han planteado -el bien, la justicia, la belleza, el amor, la muertepiden ser redefinidos, aunque no siempre con sentido. "Puede ocurrir que deseemos releer el clásico discurso de Diótima en el Banquete de Platón, una alocución sobre el peregrinaje vertical del amor. Pero, también puede ocurrir, advierte el poeta polaco Adam Zagajewski (Lvov, 1945), que una estudiante norteamericana al oír en clase este discurso por primera vez en su vida, diga de Platón: He ss such a sexist" (Zagajewski, 2005: 17). Zagajewski, crítico con lo que denomina "nuestra escéptica tía época", comenta que un estudiante que restringe el sentido del discurso de Platón se defiende del patetismo, "como si le diera miedo la fuerza destructiva de las vivencias extáticas" (Zagajewski, 2005: 21).

\footnotetext{
${ }^{1}$ Este artículo se inscribe en el proyecto 'La construcción estética de Europa' (MICINN, FFI 2010-16796), dirigido por Rafael Argullol.
} 
El campo de la Estética, aunque hoy puede parecer "una disciplina marginal que está lejos de los problemas que más directamente atañen a la realidad de nuestra existencia", sigue siendo "un observatorio privilegiado para entender nuestra situación en el mundo y en la historia" (Givone, 1990: 9). Pero las teorías estéticas contemporáneas plantean nuevas miradas con respecto a los contenidos principales de esta disciplina: arte, artista, creatividad, belleza. "Es el propio artista quien, al poner en relieve el (o, más exactamente, cualquier) objeto y situándolo en un espacio concreto, lo convierte en obra de arte", escribe Žižek, citando a Malévich como el precedente de todo arte vanguardista ${ }^{2}$. Cuando Baumgarten, por otro lado, bautizó la Estética como una disciplina filosófica independiente en 1735, su ambición fue elevar la experiencia sensitiva, unida a la creatividad artística, al nivel de una ciencia ${ }^{3}$.

Hablar con el filósofo Rafael Argullol (Barcelona, 1949) desde la óptica de los grandes temas filosóficos y estéticos para conectar con el mundo en el que vivimos, proporciona no únicamente un placer intelectual, sino sentir desde dentro para qué ha servido siempre la filosofía: aparte de cuestionar el mundo, ayuda al hombre a comprenderlo y a fortalecerse ante él.

Argullol ha vivido muchos de los grandes acontecimientos sociales y políticos de la segunda mitad del siglo XX y ha promovido, primero como estudiante activista y luego como pensador, el imperativo de construir un mundo más equilibrado y una sociedad más justa. Perseguido e incluso recluido durante la época franquista por su agitación antifascista, se exilió como estudiante en Italia y, después de licenciarse en Economía y en Ciencias de Información en Barcelona, residió en Alemania (Tübingen),

\footnotetext{
2 "La naturaleza de la obra de arte no es una cuestión de «por qué» sino de «dónde». Por tanto, lo que hace Malévich con su disposición minimalista es retratar -aislar- este espacio en sí [...] No hay Duchamp sin Malévich: solo después de que el ejercicio artístico aísle el marco/lugar-en-sí, vacío de todo contenido, puede permitirse pasar a la estrategia de lo prefabricado. Antes de Malévich, un orinal no hubiera dejado de ser un orinal, aunque lo expusiesen en la más prestigiosa de las galerías", Slavoj Žižek, consultado en: http:// samuelsotillo.com/home/2011/08/07/arte-literatura-y-las-ideas-esteticas

Consultado el 03.05.14.

${ }^{3}$ Aleksander Baumgarten utiliza por primera vez el termino aesthetica para una disciplina filosófica en su tesis doctoral Meditationes philosophicae de nonnullis ad poema pertinentibus, (Reflexiones acerca de un texto poético, Halle, 1735). En su obra más célebre, Aesthetica (1750-1758), la define como una teoría del conocimiento sensible.
} 
Reino Unido (Londres) y Norteamérica (California). El encuentro con José María Valverde (1977) orientó su carrera hacia el mundo académico, de tal modo que en 1979 se doctoró en Filosofía y Letras con una tesis sobre el Romanticismo, publicada como libro bajo el título El Héroe y el Único $(1982)^{4}$. Su trayectoria de profesor se inició en 1978 en la Universidad de Barcelona, y desde entonces ha formado largas generaciones de estudiantes representando, para muchos, una figura mítica y la más estimulante que se pueda encontrar en el paso por la Universidad. La dedicación académica de Rafael Argullol nunca ha disminuido su labor de escritor pues, además de sus 32 libros, ha sido una comprometedora voz crítica en artículos de opinión, principalmente para el diario El País. Su libro Visión desde el fondo del mar (2010), galardonado con diversos premios y que el propio escritor considera su obra maestra, se puede leer como novela autobiográfica, como novela histórica, como el género ensayístico que remite a Montaigne y, también, como yo lo definiría -aunque va más allá de todas estas calificaciones-: un libro filosófico que se basa en la experiencia de la vida.

-TD: Entre las 1200 páginas de este texto, que usted considera la culminación de su trayectoria literaria, en el capítulo "Interludio sobre este libro" leemos: "La memoria actúa, paradójicamente, como la única fuerza que empuja hacia delante. De modo que cultivamos la memoria con el obsesivo deseo de regalar algo de nosotros, por más que podamos sospechar, en las horas negras, que no habrá nadie para recibir el regalo" (Argullol, 2010: 944). ¿Puede existir la filosofia sin la experiencia de la vida?

- RA: Si nos dirigimos a los orígenes mismos de lo que llamamos filosofía en Grecia, comprobamos que hay distintas escuelas filosóficas, pero todas ellas tienen en común la unidad entre teoría y práctica, entre conocimiento y experiencia. Es decir, la filosofía no era solo una forma de conocer, sino también una forma de vivir, de construir el comportamiento humano, el carácter y, de allí, la propia ética. Por esto pienso que esa unidad de teoríapráctica es lo que caracteriza el tronco más fecundo de la filosofía. En cambio, cuando la filosofía se ha apartado de esa unidad, ha caído en determinadas degeneraciones de tipo dogmático, doctrinario o ideológico.

\footnotetext{
${ }^{4}$ El Héroe y el único fue reeditado en las editoriales: Taurus (1984; 1999), Destino (1990) y Acantilado (2008).
} 


\section{Conocimiento más experiencia}

Goethe, cuyo libro Poesía y VERDAD: SOBRE MI VIDA representa una ambición de explicar el mundo vivido y contemplado por una mente luminosa, veía que la condición necesaria para la creatividad artística o metafísica es unir la intelectualidad con la sensibilidad. "Aquel que no habla con claridad con los sentidos, tampoco lo hará con el alma", escribía, y en este contexto era crítico con Platón, por su exclusiva fe en el mundo contemplativo. Asimismo podemos observar, en la larga trayectoria de Goethe, cómo su propia obra demuestra que en el camino del desarrollo del individuo, el encuentro del hombre con el mundo es esta Bildung necesaria que no se puede sustituir con ningún conocimiento intelectual. Su Fausto -que entre la primera y la segunda parte le supuso a Goethe alrededor de cinco décadas de dedicación ${ }^{5}-$ manifiesta este camino de iniciación, asimismo autobiográfico ${ }^{6}$, que va desde la ansía de totalidad de un alma joven, a la reconciliación con el mundo y consigo mismo, donde un Goethe octogenario nos dice que "solo es libre por completo aquel que conquista su libertad a diario". Es decir, junto a la dramática confrontación con el mundo, este se abre ante el hombre si en el proceso de maduración es capaz de esforzarse en el ámbito cotidiano al aprender lo que puede y lo que no.

- TD: ¿Vivir, actuar, aprender y asumir los límites? ¿Es este mensaje válido para cualquier hombre y cualquier época?

- RA: Soy un admirador incondicional de la obra literaria de Platón, es decir, de Platón como escritor. Sin embargo, en algún aspecto estoy completamente

\footnotetext{
${ }^{5}$ La primera versión del mito de Fausto elaborado por Goethe, conocido como el Urfaust, ocupó al escritor entre 1772 y 1775. En 1790 apareció Fausto, un fragmento. No obstante, Fausto, Primera parte no fue terminada por Goethe hasta el 1806 y se publicó en 1808. En 1828-1829 salió una versión revisada, la última editada por el propio Goethe. La segunda parte de Fausto le ocupó hasta el año de su muerte, acontecida en 1832.

${ }^{6}$ En el género autobiográfico "en la primera década del siglo XXI están surgiendo nuevas orientaciones, cuyas principales aportaciones proceden del campo de la neurociencia", como explica la profesora Anna Caballé, directora de la Unidad de Estudios Autobiográficos en la Universidad de Barcelona, citando teorías de diversos científicos como Carlos Castilla del Pino, entre otros. Afirma Caballé: "Castilla del Pino, en su magnífico estudio Teoría de los sentimientos (Tusquets, 2000) [...] defendía la idea de que era la memoria autobiográfica quien sostenía la identidad, el Yo, más allá de todas las transformaciones personales" (Caballé, 2012: 27-28).
} 
en contra de sus posiciones, como cuando cree que un hombre en una sociedad ideal tiene que jugar un solo papel. Yo defiendo mucho más lo que sería una perspectiva de tragedia como 'paidea'. En mi opinión, un hombre llegaría a conocerse mínimamente si al final de su vida hubiera sido capaz de representar todos los papeles de la tragedia y todos los papeles de la comedia. Platón filósofo, despierta en mí posiciones contrapuestas.

En cambio, reconozco que soy muy goethiano. Su obra representa la construcción intelectual de alguien que a lo largo de los años es capaz de ir modificando sus propias posiciones, autocriticando sus concepciones. A medida que se desarrolla su vida, que va paralela al avance final del 'Fausto', Goethe llega a unas conclusiones que me parecen de las más interesantes que se hayan podido esbozar en la historia de la cultura: el hombre debe de aceptar creativamente la función del mediador entre lo visible y lo invisible, entre el mundo de los pensamientos y el mundo de las sensaciones. A partir de esta idea o de esta complicidad, en mi propia obra siempre he tratado de realizar una ósmosis entre el ámbito de las ideas y el ámbito de las imágenes. En lo que llamo la 'escritura transversal', casi siempre intento traducir el pensamiento en imágenes. Y, por otro lado, procuro que una sensación tenga su traducción en ideas. Comparto con Goethe un profundo monismo filosófico, que defiende la unidad del cuerpo y del espíritu así como en la unidad del pensamiento y la sensación.

\section{Heráclito vs. Parménides}

LA VISIÓN DIALÉCTICA DE QUE TODO ESTÁ en un permanente movimiento frente al principio de eternidad marca otras dos vías de pensamiento en la historia de la filosofía occidental. Pero entre el 'Todo cambia' de Heráclito y el ser, uno, eterno e inmutable que promueve Parménides, Rafael Argullol nos habla de lo 'uno y lo múltiple' en su libro Del Ganges al Mediterráneo: "La física moderna ha actuado por penetración y por análisis y al mismo tiempo ha intentado realizar una síntesis. [...] En toda la tradición occidental el ser sería la traducción cósmica, aunque a veces intangible e invisible, de esta jerarquía. Por lo tanto, el ser sería aquello que integraría la dialéctica entre lo uno y lo múltiple, y sospecho que el ser en Occidente equivale al vacío de algunas tradiciones orientales" (Argullol, 2004: 65). En El Héroe y el único Argullol vincula al espíritu del romanticismo esta dinámica entre nuestra ansía de afirmarnos en lo individual y de integrarnos en lo universal: "La comprensión de lo limitado de la condición humana deviene resignación o 
nihilismo si no está acompañada por la voluntad heroica de lo ilimitado" (Argullol, 2008: 19).

- TD: ¿Puede un hombre que vive hoy creer en la ontología del ser, tal como lo planteaba Parménides, Leibniz, el idealismo alemán?

- RA: Si nosotros observamos un gran río, para poner como ejemplo uno cercano a Barcelona: el Ebro, desde muy corta distancia tenemos una visión de la realidad completamente fluyente. En cambio, si observamos el Ebro desde un satélite artificial, o desde la luna, tenemos una visión estática casi inmutable de aquella imagen que tenemos delante.

Yo creo que tanto Parménides como Heráclito tenían razón. Son las dos caras del ser. Por un lado, el ser se manifiesta en su inmutabilidad, en su unidad y en su eternidad y, por otro, se expresa en su diversidad y contingencia. Baudelaire describió esto perfectamente en el ensayo 'El pintor de la vida moderna' (1863) al retratar un tipo de hombre que avanza continuamente a través de una tensión y una contradicción porque es un hombre que busca lo universal y lo fragmentario. En cierto modo, algo de esto he aplicado en mi metodología literaria, pues hurgo en las capas internas de la realidad a través de un microscopio de la palabra. Cuando llego a una excesiva intimidad giro la lente y convierto el microscopio en telescopio y busco lo más universal. Y cuando llego a lo universal que roza lo abstracto, giro la lente de nuevo, y voy a lo particular. La existencia es tanto aquello que nos proporciona el telescopio como el microscopio; aquello que nos proporciona la visión inmutable de Parménides, como aquello cambiante que nosotros anclamos en Heráclito.

\section{Una filosofía nómada}

La tragedia griega, los ENSAYOS de Montaigne y los dramas de Shakespeare son obras literarias profundamente filosóficas; en Rusia, por ejemplo, jamás ha existido una tradición de filosofía sistemática, pero sí, con las novelas de Dostoyevski y Tolstói, la más filosófica de las literaturas.

- TD: Usted, fascinado además por las grandes figuras renacentistas siempre ha sido partidario de este espiritu renacentista, amplio, universal, en la cultura, en el arte y por supuesto en la filosofía. ¿A un estudiante actual recomendaría empezar con las lecturas de Kant y Hegel o Shakespeare y Dante? 
- RA: Cuando yo empecé a dar clases en la Facultad de filosofía de la Universidad de Barcelona, que se autodenominaba 'Facultad de filosofía pura' - la única facultad de filosofía que he visto en el mundo con una denominación tan radical- a mí me encargaron un programa de historia de la filosofía para los del primer curso, en el cual puse al lado de los presocráticos, de Platón y de Aristóteles, a Esquilo y a Sófocles. Asimismo, introduje a Montaigne y a Shakespeare junto a los neoplatónicos del Renacimiento. Y, al lado de Heidegger, a Camus, Joyce o Valéry.

Desde el principio yo aposté por una filosofía que rompiera las barreras puramente doctrinarias. Esto causó cierto escándalo entre los profesores más estrechos de miras, pero ha sido el principio que me ha guiado siempre. Para un estudiante que se abre al estudio de la filosofía, y en general al estudio del pensamiento, es tan útil el estudio de las obras de Hegel y de Kant como las obras de Sófocles, de Shakespeare o de Albert Camus.

\section{- TD: ¿Es por esto que siempre rehúye de firmar sus artículos como} 'filósofo' y opta por 'el escritor'?

- RA: A lo largo de estos años he tenido que sufrir el hecho de que me pusieran diversas etiquetas. Me he visto firmando como poeta, como filósofo, como ensayista. Finalmente, decidí que cuando yo pudiera elegir, pondría el título de escritor, porque me parece el más laico, el más humilde; es lo que mejor describe lo que uno está haciendo, que es el vínculo con la escritura y con la palabra.

Por OTRO LADO, ESTÁ HÖLDERLIN, cuya poesía y pensamiento revelan un alma sensible en extremo, posiblemente origen de su dramático destino. Pasó los últimos 35 años de su vida como un "loco". " "Finalmente me cansé de

\footnotetext{
${ }^{7}$ Desde 1807 hasta su muerte, Hölderlin vivió en casa de Ernst Zimmer, un carpintero ebanista que admiraba Hiperión y hacía trabajos para la clínica donde habían internado al poeta un año antes y después declarado loco. "Si se ha vuelto loco, no es por falta de espíritu, sino a fuerza de saber. [...] Esos malditos libros, todo el día abiertos sobre la mesa, y cuando está solo, desde por la mañana hasta por la noche se lee a sí mismo pasajes en voz alta, declamando como un actor, con aires de querer conquistar el mundo" (Hölderlin, 1993: 34) explicaba Zimmer, que dejó un testimonio directo acerca del estado de Hölderlin en estos años, explicando que seguía escribiendo versos y cartas, tocando música, conversando -aunque de modo discontinuo.
} 
volcarme buscado uvas en el desierto y flores en los ventisqueros [...] Lo incurable del siglo, por las cosas que cuento y por otras que me callo, se me había hecho evidente, y el hermoso consuelo de encontrar mi mundo en un alma, de abrazar a mi especie en una criatura amiga, me faltaba también", leemos en Hiperión (Hölderlin, 1993: 43). Parece coherente que el autor de versos similares busque una salida ante la prosa de las circunstancias en la demencia.

- TD: ¿Qué queda hoy del espíritu de Hölderlin? ¿Usted le sigue sintiendo a su lado a menudo?

- RA: Cuando se lleva escribiendo muchos años, al final, cuando te preguntan quién te ha influido ya no sabes que contestar. En realidad, lo que te acompaña es una especie de hermandad de sombras cómplices, que están presentes en tu obra, muchas veces incluso involuntaria o inconscientemente. No hay duda que entre los cómplices que yo me he encontrado en el camino, uno de los que más profundamente me ha conmovido y, al mismo tiempo, uno de los más luminosos es Hölderlin. Aún siento su cercanía de una manera muy constante. Además, Hölderlin fue muy coherente en el momento de construir una razón mítica que finalmente él mismo abrazó en su propia vida. A pesar de que pueda parecer paradójico a muchos, yo creo que Hölderlin es de nuestros compañeros de viaje más cercanos.

Viajes

En su faCETA De VIAJERO, Argullol ha estado muchas veces en Rusia, Serbia y otros países eslavos, sobre ello ha comentado que al Oriente de Europa le falta más espíritu cartesiano.

- TD: ¿Qué herencia de Descartes, de su Discurso de método (1637), se siente hoy en Occidente? Si recordamos el destino final de este padre del racionalismo filosófico, a quien el ansia de la reina de Suecia de que la instruyera personalmente - con la dureza del clima sueco y la estricta disciplina del trabajo- le costaron la vida, iparecería ser que no siempre

\footnotetext{
${ }^{8}$ René Descartes, que pasó la mayor parte de su vida en Holanda, se trasladó a Suecia en 1649 en un barco enviado por la reina Cristina de Suecia, quien atraída por la filosofía cartesiana pidió trasladar al filósofo a su lado. A Descartes no le agradaba el clima sueco y el horario de clases, que iniciaba a las cinco de la madrugada, éstas le acabaron agotando
} 
los grandes filósofos defienden con su experiencia vital las enseñanzas que propagaron?

- RA: Para conseguir en el futuro una auténtica síntesis de Europa se necesita que la Europa del Este sepa más de Descartes y la Europa Occidental sepa mas de Dostoyevski; hacer una especie de matrimonio entre Descartes y Dostoyevski. Creo que Descartes, como en parte le ocurre a Platón, está en cierto modo dominado por un prejuicio semántico. Generalmente hablamos del cartesianismo como de un híper racionalismo pero, en realidad, Descartes fue un gran estudioso de las pasiones humanas y, de hecho, el año que murió en Suecia, completó su Tratado de las pasiones del alma.

La herencia de Descartes en la Europa moderna es precisamente esa posibilidad de conciliar pasión y razón. Pero nuestra época ha desarrollado una mentalidad en la cual el racionalismo ha degenerado en pragmatismo y utilitarismo y, además, la pasión ha degenerado en sentimentalismo. Se echa de menos el ideal de la conciliación de Descartes.

\section{Fe y religión}

Rafael Argullol tuvo una educación católica, aunque en sus escritos ha sido muy crítico con la misma. A pesar de ello, su último libro se titula Pasión del dios que quiso ser hombre en el que revela una profunda fascinación por la historia de la Pasión de Cristo. Hacia el final de este libro, leemos: "Se ha escrito la última página del último capítulo. Pero ¿es esa la verdad? Ahora deberás convencer a los hombres, y convencerte a ti, que nunca hay una última página y un último capítulo, y que lo que muere, renace. ¿Será esto la verdad?" (Argullol, 2014a: 79).

- TD: Parece que Usted deniega siempre de la Iglesia, o de las diferentes iglesias cristianas. ¿Es porque todas están lejos de concebir que Dios tendría que comprenderse igual que la libertad, para parafrasear a Spinoza? ¿Ha sentido al menos la presencia de un daimon interior, o Rafael Argullol es un hombre que se ha creado enteramente a si mismo?

y aquel provocó en él una neumonía, de la que murió en Estocolmo en 1650, el mismo año que concluyó Tratado sobre las pasiones del alma. 
- RA: Mi último libro, Pasión del dios que quiso ser hombre se subtitula 'Un relato y una confesión'. En el 'Relato' hago una reescritura de la historia de Cristo, casi como si fuera un héroe trágico griego. En la segunda parte de texto, llamado 'Confesión', explico por qué escribo el relato. La Pasión de Cristo y la figura de Cristo han tenido para mí una fascinación permanente. Es ahí donde manifiesto que tras mi educación católica, en los años de militancia revolucionaria, adopté -como muchos- una actitud atea. Poco después me pareció que el ateísmo era una pereza intelectual y lo abandoné por el agnosticismo. Años después abandoné también el agnosticismo como otra faceta de la pereza intelectual.

Actualmente digo que soy creyente en dioses transitorios, es decir, creo en esa profunda unidad entre lo sensitivo y lo espiritual de la que hablaba antes. En ese sentido, yo siempre he reivindicado que la fe no debe de dejarse únicamente en manos de las religiones. El espíritu no es un monopolio de las religiones, sino fundamentalmente algo que concierne a los hombres que quieren ser libres. En ese sentido, diría que mi dios es próximo a la concepción de Spinoza. Y por otro lado, muchas veces me he sentido acompañado por un 'daimon' o por un ángel de la guarda, o por una voz que en mi propio interior va dialogando conmigo acerca de lo que pueda ser la propia existencia.

\section{Arte y belleza}

La Afirmación De Dostoyevski, "La Belleza salvará el mundo", se ha reivindicado mucho, aunque no siempre se entiende que el escritor ruso se refería a la gran cultura, al balance que las mentes creativas e ilustres siempre han proporcionado para que -incluso en los momentos históricos más dramáticos- el mundo no estalle en pedazos, y nosotros con él también. En la estética de Platón, no obstante, este refugio siempre está a un nivel inteligible, lejano e inaccesible para la mayoría de los mortales; podemos deleitarnos con lo bello, pero la Belleza en sí es solo una idea que únicamente el filósofo puede conocer. Para el cineasta ruso, Andréi Tarkovski, el arte nace de la imperfección de la vida y "nos da fuerza en un mundo monstruosamente cruel, que roza, en su sinrazón, el absurdo".

- TD: ¿Con cuál de estas posturas se siente más identificado? ¿Algunas son más anacrónicas que otras? 
- RA: Yo creo que la belleza es la consecuencia del enigma. Y el enigma es la consecuencia de que en un determinado momento un animal adquirió conciencia de la muerte y luego, también, conciencia de la vida y del paso del tiempo. El fruto de eso es que este animal consciente de la muerte y de la vida que llamamos hombre, intentó entender el significado de su propia existencia y, por lo tanto, se confrontó con lo que llamamos el 'enigma', que en su sentido etimológico señala lo que se vela y lo que se revela.

Cuando Dostoyevski dice que "La Belleza salvará el mundo", entiendo siempre que es nuestra conmemoración del enigma lo que salvará el mundo. Cuando Tarkovski habla de esa imperfección perfecta, o esta perfección imperfecta, también se refiere a la belleza del enigma. Aunque Platón puede tener fama de haber adoptado una posición distante y contemplativa, en el diálogo decisivo de Platón, El Banquete, se explica nuestro acceso a la Belleza en sí misma. Y quien introduce a Sócrates a la Belleza es Diótima, una extranjera y una mujer. Esto quiere indicar que, en cierto modo, es la otredad lo que se impone a lo que era propio al discurso griego ortodoxo. En la escalera de la Belleza el iniciado llega al último escalón, que le permitirá contemplar la Belleza en sí misma; Platón no lo describe, sino que dice que esto se producirá precisamente a través de un acto místico. Los tres nombres que usted ha citado, Tarkovski, Dostoyevski y Platón, están engarzados a través de la atracción del enigma y de la belleza del enigma.

\section{Amor}

PLATÓN CONSIDERA QUE LA EXPERIENCIA ERÓTICA es una de las vivencias concretas que nos puede aproximar a lo ideal. En el Fedro describe con minucioso detalle el estado del enamoramiento. Dice que a nuestra alma, cuando ama, le empiezan a crecer alas "como con esa sensación que tienen los que están echando los dientes cuando ya van a romper" (Fedr. 251c1), pero entonces "se aflige ante lo absurdo de lo que le pasa, y no sabiendo por donde ir, se enfurece, y, así enfurecida, no puede dormir de noche ni parar de día [...] olvidándose de madre, hermanos y amigos todos" (Fedr. 251d10), tal como ilustra la 'manía' amorosa.

- TD: ¿Usted, como filósofo, cree en los peldaños de la iniciación amorosa que ofrece Platón en El Banquete, que presuponen que el eros de un amor concreto empuja hacia el amor al conocimiento intelectual? 
- RA: Lo que habitualmente llamamos 'el sabio', está siempre asentado en una gran contradicción. Sea en la tradición hindú, en la tradición budista o en la tradición griega platónica, el sabio es aquel que se ha situado más allá de las pasiones. El problema es que si hay un hombre que verdaderamente llega a esa situación creo que enseguida tendría envidia de la época en la que estaba sumido a las pasiones. Es lo que en el mundo cristiano se ha reflejado siempre en las historias de los sabios ascetas solitarios, movidos por la tentación de la sensualidad: San Jerónimo, San Antonio y otros.

Está claro que en Platón había dos pensadores completamente antagónicos: uno que quería situar al sabio más allá de las pasiones, y otro que le otorgaba al enamorado una de las formas de posesión divina. Por ello hay que remitirse al significado mismo de la filosofía: el filósofo como el amante del saber. Aquel que considera que se ha situado mas allá de todas las pasiones es peligroso; indudablemente esta poseído por alguna de las pasiones más negativas.

SPINOZA INSTRUYE QUE "El amor no es sino la alegría, acompañada por la idea de una causa exterior" (Spinoza, 1986: 193). Estamos dotados de la razón precisamente para entender, según la concepción de las pasiones expuesta en su Ética, que cuando en la experiencia amorosa uno se enfrenta a una barrera insalvable, el amor se apaga, o se convierte en odio. Y que solo podemos denominar amor si es un sentimiento que aumenta tanto la potencia de obrar de nuestro cuerpo, como la potencia de pensar de nuestra alma.

\section{- TD: ¿Platón o Spinoza para aproximarse a la experiencia del amor?}

- RA: El joven Platón quiso ser un poeta trágico y el viejo Platón expulsó a los poetas trágicos de la ciudad ideal. Algo parecido le sucede con el eros. Spinoza es mucho más coherente. Para Spinoza el amor forma parte de su necesidad de buscar las pasiones afirmativas de la vida y de rehuir a las negativas. La definición spinoziana del amor sería casi la vanguardia de las pasiones afirmativas del amor. Cuando Spinoza nos habla del amor nos habla de esa cualidad de afirmación vital que empieza por el hecho del amor propio porque solo aquel que se ama a sí mismo tiene un superávit de amor como para amar a los demás. 


\section{Escenario político}

Si bien Platón vivió en la Grecia de la polis y la obra aristotélica respira, en gran medida, el espíritu cosmopolita del helenismo, que supuso el intercambio de la cultura griega con otras culturas, ambos prestan suma atención a la cuestión política. Sabemos que en la utopía política expuesta en la República de Platón, se pensaba que solo el filósofo podría liderar a un estado ideal y a una sociedad auténticamente justa.

-TD: ¿Qué reflexión le merece el escenario político universal? ¿Es optimista o pesimista respecto al futuro, en relación al presente y al pasado?

- RA: Si pudiera acogerme a las ciudades ideales pintadas por Piero della Francesca, me acogería al hecho de que la ciudad ideal tiene que ser gobernada por sabios. Pero, por otro lado, al reconocer la imperfección de la condición humana -tanto individual como colectiva-, reivindico también la democracia como el único gran contrato político que se ha concebido para seres imperfectos como los hombres. No obstante, la democracia de los seres imperfectos tomada abusivamente, acaba en demagogia, o en ese utilitarismo pragmático al que asistimos en nuestros días.

SHAKESPEARE POSIBLEMENTE NO HUBIERA TENIDO IGUAL MOTIVACIÓN LITERARIA Si no hubiera habido algo de este "podrido en Dinamarca", expandido por toda su tierra, que le empujaba a denunciarlo a través de sus representaciones teatrales. Las cartas sobre la educación estética de la humanidad de Schiller es otro ejemplo de un magnífico texto filosófico que nace en las hogueras de las rebeliones sociales mal encaminadas, o mal dirigidas.

Rafael Argullol ha sido siempre un pensador comprometido con su época. En uno de sus últimos artículos de opinión, leemos: "El problema es que la universidad actual se ha convertido, por inseguridad, cobardía u oportunismo, en cómplice pasivo de la actitud anti-intelectual que debería combatir [...]. Es llamativo, a este respecto, la escasa aportación universitaria a los conflictos civiles actuales, incluidas las crisis sociales o las guerras" (Argullol, 2014b).

- TD: ¿Si ahora le encargaran ocuparse de la política ¿qué modelo y a qué figura histórica seguría? 
- RA: Actualmente, mi idea política prioritaraminete es una Europa unida. Si yo pudiese imaginar un proyecto político, propondría una Europa que fuera una red de ciudades-estado similar a la que había en el Renacimiento o en la Antigüedad clásica. Creo que la cercanía de la administración es esencial para preservar la libertad, y este sistema va en esta dirección. Mi lema actual sería una polis que se rigiera por el conocimiento y la democracia directa. Si tuviera que rescatar una figura política iría lejos: a Pericles, sencillamente porque le llamaban 'el Incorruptible'.

\section{El tiempo}

EN VISIÓN DESDE EL FONDO DEL MAR, está muy presente el tema del tiempo, aunque hacia la última parte del texto, Argullol concluye: "El tiempo no existe, ya lo sabéis. Lo hemos inventado primero para poder jugar en la arena, primero con una maravillosa inconsciencia y luego, a medida que se aproxima el momento de irnos, con una mezcla de cautela y osadía. Nos gusta construir nuestros pequeños castillos. En ellos domesticaremos el tiempo" (Argullol, 2010: 954).

- TD: Leyendo su obra parece ser que usted ha vivido de acuerdo con la postura de entender que la vida es un lapso dado al ser humano para realizarse en aquello que está predestinada su alma de modo aristotélico.

- RA: Hay que vivir como si fuera el último día porque de lo contrario se nos desliza la vida y no la podemos atrapar. Pero hay que vivir como si fuéramos eternos porque de lo contrario somos incapaces de realizar grandes proyectos creativos.

"LA MUERTE No es UnA DesGracia, sino UnA ventura", leemos que dice Sócrates antes de despedirse de la vida, aunque también lo matiza, según explica Platón en Apología de Sócrates: "Una de dos: o bien la muerte nos deja reducidos a la nada, sin posibilidad de ningún tipo de sensación, o bien, de acuerdo con lo que algunos dicen, simplemente se trata de un cambio o mudanza del alma de este lugar hacia otro".

\footnotetext{
${ }^{9}$ La intertextualidad de estos versos de la Apología de Sócrates se puede seguir en San
} 
- TD: ¿La filosofia y la literatura también preparan al hombre para aceptar la idea de la muerte?

- RA: La cultura en general es una conciencia de la muerte pero, también, una rebelión y una protesta contra ella. Aunque hayan tenido distintas máscaras, hay un hilo conductor en todas las formas de arte de las diversas épocas. Desde el arte de las pinturas rupestres hasta lo que auténticamente se entiende como el arte en nuestros días, el hombre se confronta con la muerte, pero no solo aceptándola sino, también, protestando contra ella. El arte nace de esa tensión. Y la filosofía es una preparación de la muerte y una protesta contra la muerte.

En Nacimiento de la tragedia, Nietzsche tiene una frase extraordinaria que viene a decir que cuando el hombre, precisamente a través de la conciencia de la muerte y de la fugacidad, estuvo a punto de destruirse, se acercó al arte como un mago que cura y salva. Y ahí vemos la función profunda del arte, que es la conciencia de nuestra fugacidad pero, al mismo tiempo, sirve para curarnos la herida de la fugacidad. Por eso, quizá una de las expresiones más elevadas de arte que ha habido en la historia humana es la tragedia griega, que es la demostración de la herida y de la catarsis respecto a esta herida.

Este diálogo con Rafael Argullol fue grabado en el Instituto Universitario de Cultura de la Universitat Pompeu Fabra el 3 de mayo de 2014.

Agustín, Montaigne, Shakespeare. En Sobre el libre arbitrio, San Agustín dice que nosotros preferimos la vida, porque tenemos miedo a lo desconocido que representa la muerte (III, VI, 19). En el más conocido monólogo de Shakespeare, cuando Hamlet plantea "To be, or not to be", a continuación vacila sobre distintos destinos que esperan el hombre al morir; evoca a Platón y a Montaigne, que hablan de la muerte como de un descanso sin sueños, solo reposo; "To sleep, to sleep, perchance to dream", pronuncia Hamlet, preguntándose si no es, quizá, un reposo con sueños. En Apología de Sócrates, Platón había escrito: "Si la muerte es la extinción de todo deseo y como una noche de sueño profundo, pero sin ensoñaciones, ¡qué maravillosa ganancia sería!". 


\section{Referencias}

Argullol, R. (2014a). Pasión del dios que quiso ser hombre. Un relato y una confesión. Barcelona: Acantilado.

Argullol, R. (2014b). La cultura enclaustrada. El país, 4 de abril. Consultado el 04.05.14. Versión online: http:/elpais.com/elpais/2014/03/25/ opinion/1395742979_031566.html.

Argullol, R. (2010). Visión desde el fondo del mar. Barcelona: Acantilado.

Argullol, R. (2008). El Héroe y el único. Barcelona: Acantilado.

Argullol, R. \& Mishra, V.N. (2004). Del Ganges al Mediterráneo, Un diálogo entre las culturas de India y Europa. Madrid: Siruela.

CABallé, A. (2012). Malestar y autobiografía. Círculo de Lingüística aplicada a la Comunicación. No. 50.

Givone, S. (1990). Historia de la estética. Madrid: Tecnos.

Goethe, J.W. (2009). Poesía y Verdad: sobre mi vida. Barcelona: Alba.

Hölderlin, F. (1993). Hiperión o El eremita en Grecia. Madrid: Ediciones Hiperión.

Platón. (1997). Diálogos III. Madrid: Editorial Gredos.

SpinozA, B. (1986). Ética. Barcelona: Ediciones Península.

Zagajewski, A. (2005). En defensa del fervor. Barcelona: Acantilado. 